\title{
Bağımsızlığa Adanmış Bir Hayat: Küçüm Han
}

\section{A Life Dedicated to Independence: Kuchum Khan}

\author{
İlyas Topsakal* ${ }^{*}$, Mecnun Tarık Y1lmaz ${ }^{* *}$ (])
}

*Prof. Dr., İstanbul Üniversitesi, Edebiyat Fakültesi, Tarih Bölümü, Genel Türk Tarihi Ana Bilim Dalı, İstanbul, Türkiye

*Doktora Öğrencisi, İstanbul Üniversitesi, Edebiyat Fakültesi, Tarih Bölümü, Genel Türk Tarihi Ana Bilim Dalı, İstanbul, Türkiye

ORCID: I.T. 0000-0003-1415-4898 M.T.Y. 0000-0002-2002-235X

\footnotetext{
Sorumlu yazar/Corresponding author: İlyas Topsakal, İstanbul Üniversitesi, Edebiyat Fakültesi, Tarih Bölümü, Genel Türk Tarihi Ana Bilim Dalı, Istanbul, Türkiye

E-posta/E-mail: ilyastopsakal@yahoo.com

Başvuru/Submitted: 31.07 .2021

Kabul/Accepted: 29.09 .2021

\section{Atıf/Citation:}

Topsakal, llyas ve Yilmaz, Mecnun Tarik.

"Bağımsızlığa Adanmış Bir Hayat: Küçüm Han." Tarih Dergisi - Turkish Journal of History, 75 (2021): 17-31.

https://doi.org/10.26650/iutd.976868
}

\section{Öz}

Şeybani soyundan gelen Küçüm Han, 1563 yılında Sibir Hanlığı'ndaki Taybuga hâkimiyetine son vermiştir. İktidarının ilk yıllarını ağabeyi ile birlikte paylaşmasından dolayı daha çok devletin iç meselelerine yoğunlaşan Küçüm Han, ağabeyinin ölmesiyle birlikte devletin dış meseleleriyle de uğraşmaya başlamıştır. Böylece Moskova'nın 1552 yılında Kazan Hanlığı'nı işgal etmesiyle birlikte Sibirya'ya doğru hız kazanan Rus ilerleyişini durdurmayı kendisine amaç edinmiştir. Bu amacını gerçekleştirmek için ise, Buhara ve Kazan'dan gelen din adamları başta olmak üzere, Sibirya'nın yerli kabilelerinin yardımına ihtiyaç duymuştur.

1573 yılından itibaren din adamlarının ve yerli kabilelerin desteğini alan Küçüm Han, 1582 yılına kadar Sibirya'da son derece başarılı mücadeleler vermiş̧tir. Ancak mücadelelere Stroganovların ve Kozakların dahil olması durumu tersine çevirmiştir. Kozakların, İsker'i işgal etmesi sonucu şehri terk etmek zorunda kalmıştır. 1584 yılında Kozak Ataman'ı Yermak Timofeyeviç'i öldürmeyi başarsa da şehri geri alamamış; ama buna rağmen Yermak Timofeyeviç'in ölümünden sonra Sibirya'ya gelen merkezi Rus birlikleriyle 1598 yılına kadar mücadele etmeyi sürdürmüştür.

Anahtar sözcükler: Sibirya, Küçüm Han, Bağımsızlık, Stroganovlar, Kozaklar

\section{ABSTRACT}

Kuchum Khan, a descendant of the Shaybanids, put an end to the rule of Taibugids in the Sibir Khanate in 1563. Kuchum Khan, who had focused more on the internal affairs of the state because he shared the first years of his rule with his brother, started to deal with the foreign affairs of the state on the death of his brother. Thus, with the invasion of the Kazan Khanate by Moscow in 1552 , he aimed to stop the Russian advance toward Siberia. Achieving this goal required the help of the indigenous tribes of Siberia, especially clergy from Bukhara and Kazan.

Kuchum Khan, who had received the support of clergy and indigenous tribes since 1573, had extremely successful confronations in Siberia until 1582 but the involvement of Stroganovs and Cossacks in the struggles reversed the situation. Cossacks had to leave the city as a result of the occupation of Isker. Even though he succeeded in killing the Cossack Ataman Yermak Timofeyevich in 1584, Kuchum Khan could not take the city back. Despite this, after the death of Yermak Timofeyevich, he fought the central Russian troops who arrived in Siberia until 1598.

Keywords: Siberia, Kuchum Khan, Independence, Stroganovs, Cossacks 


\section{Extended Abstract}

In the thirteenth century, lands of the Ishim, Tobol, Irtysh, and Tura Rivers, were handed over to the Kyrgyz nobleman Taibuga, son of Mamık by Genghis Khan. Taibuga established an autonomous country centered on Chimgi-Tura (the current Tyumen) and his successors Hodja Khan and Mar Khan carried on his legacy. However, in time, Taibugids domination was threatened by the Shaybanids, who wanted to take over this country. Thus began the conflict for domination between the Taibugids and the Shaybanids. Although the Shaybanids sovereign Ibak Khan did take the country on 1468, he could not hold it for long and lost it back to the Taibugas in a short time.

Following this struggle with the Shaybanids, the Taibugids decided to foster close relations with Moscow to keep their domination strong. Therefore, Moscow was gaining control, first by occupying the Kazan Kaganate in 1552 and the Astrakhan Kaganate in 1556 but also by sending the Russian immigrants and miners to Perm, even spreading through Siberia. Nevertheless, in 1557-1558, Kuchum Khan, who wanted to obtain Sibir Kaganate, put an end to the Taibugids and Moscow's hopes of possessing this country and in 1563 put an end to the rule of the Taibugids in the Siberian Khanate.

Conversely, different opinions have been expressed about the genealogy of Kuchum Khan, and historians are divided over this. The first of these views was formed on the basis of some events relating to Kuchum Khan and that Kuchum Khan was connected to the Kazakh Horde lineage. As it happens, some of the historians who expressed this thought acted independently of the information given in the main sources, while others simply misinterpreted the main sources. The second opinion about the ancestry of Kuchum Khan is that he belonged to the Shaybanids. This view was first put forward by Kadir Ali Bek Celayiri in 1602, and then Abu'l Gazi Bahadir Han made some alterations regarding the family members of Kuchum Khan in line with the same opinion. Despite this, the information given by these two people about the ancestry of Kuchum Khan caused some mistakes when considered within the framework of main sources and logic. Aware of these mistakes, Sh. Marcani made new inferences about the family members of Kuchum Khan by synthesizing the information given by Kadir Ali Bek Celayiri and Abu'l Gazi Bahadır Han within the framework of his research over time. As a result, although Kadir Ali Bek Celayiri and Abu'l Gazi Bahadır Han and Sh. Marcani have expressed various opinions about the family members of Kuchum Khan, it is still valid today, although it is certain that Kuchum Khan is descended from the Shaybanid dynasty.

Thus, Kuchum Khan, whom sources confirm as a descendant of the Shaybanids, put an end to the rule of Taibugids in the Siberian Khanate in 1563. Kuchum Khan, who had focused more on the internal affairs of the state because he shared the first years of his rule with his brother, started to deal with the foreign affairs of the state on the death of his brother. 
Therefore, with the invasion of the Kazan Khanate by Moscow in 1552, he aimed to stop the Russian advance toward Siberia. Achieving this goal required the help of the indigenous tribes of Siberia, especially clergy from Bukhara and Kazan.

Kuchum Khan, who received the support of the clergy and local tribes from 1573 , conducted extremely successful struggles in Siberia until 1582. However, the fact that the Stroganovs, whose businesses were damaged by the attacks of Kuchum Khan, and the Cossacks, who were supported financially by the Stroganovs, participated in these struggles reversed the situation. Although Kuchum Khan fought with the Cossacks who left the Stroganovs' households in Chusovo on September 1, 1582, he was forced to leave the city on October 26, 1582, as a result of the occupation of Isker by the Cossacks. Despite this, Kuchum Khan, who was determined to ensure the independence of the Sibir Khanate, attacked the Cossacks with various tactics applied in the steppe and managed to both wear out the Cossack troops and kill various Cossack Atamans at different times. As can be seen, from 1584, the gradual loss of important leaders of the Cossack troops and the emerging food problem confirm the success of Kuchum Khan and his subordinates.

After these events, Kuchum Khan made an agreement with the people of Bukhara to deal the final blow to the Cossacks in June 1584 and succeeded in killing the Cossack Ataman Yermak Timofeyevich in an ambush set up on the Vagay River. However, due to the struggle for power in the Siberian Khanate, Kuchum Khan could not take back the Isker. Despite this, after the death of Yermak Timofeyevich, Moscow, taking advantage of the power struggles in Siberia, continued the process leading to the Russian domination of the region with the military governors it sent to Siberia. Thus, while Moscow was building various Russian cities in the region, it struggled with Kuchum Khan and his followers. Despite this, Kuchum Khan, who was determined to expel the Russian central troops as well as expelling the Cossacks from Siberia, fought the central Russian troops until 1598. As of that year, there were not enough soldiers around Kuchum Khan and sources indicate that the lands of the Mangits, namely, the Nogay Orda, were lost.

In our study, first of all, under the title "Kuchum Khan's Genealogy," the opinions expressed on whether Kuchum Khan is a Kazakh or a Shaybanid will be assessed, then, under the title "Life of Kuchum Khan," information will be presented about the wars that involved Kuchum Khan and his sense of independence. 


\section{Giriș}

XIII. yüzyıldan itibaren Moğolların batı seferleri sonucu ele geçirilen İşim, Tobol, İtiş ve Tura Nehirlerinin olduğu topraklar Cengiz Han tarafından Kırgız asilzadelerinden Mamık oğlu Taybuga'ya verilmiştir ${ }^{1}$. Böylece bu topraklar üzerinde Çimgi-Tura (Bugünkü Tümen $)^{2}$ merkezli bir otonom bölge oluşturan Taybuga'dan sonra sırasıyla onun soyundan gelen Hoca Han ve Mar Han bu bölgeyi yönetmeye devam etmişlerdir ${ }^{3}$. Fakat bir süre sonra bu topraklar üzerinde söz sahibi olmak isteyen ve Şeybani soyundan gelen İbak Han, Taybuga soyundan gelen Mar Han'1 öldürüp oğulları Muhammed ve Angış Han'ı kendi sarayında tutsak etmiştir ${ }^{4}$. Buna rağmen bölgedeki Şeybani hâkimiyeti uzun sürmemiş, esaretten kurtulmayı başaran Muhammed ve Angış Han, İbak Han’ı öldürmüşlerdir. Bu olaydan itibaren bölgenin hâkimiyeti yarım asır Taybuga soyundan gelen Muhammed, Kasım, Angış, Yadigâr ve kardeşi Bek Bulat Han'da kalmıştır. Fakat 1557 yılında Yadigâr Han'ın, Rus Çar'ı IV. İvan'a Şeybani Hanı ile savaş halinde olduğunu söylemesinden ${ }^{5}$ anlaşıldığı üzere Şeybani tehdidinin Taybugaların Sibirya'daki hâkimiyetini yeniden tehlikeye soktuğu görülmektedir. Nitekim aradan çok zaman geçmeden 1563 yılında Küçüm Han, Sibir Hanlığı'ndaki Taybuga hâkimiyetine son vererek, yönetimin tekrar Şeybani soyuna geçmesini sağlamıştır.

İktidarı sırasında Küçüm Han, Rusların 1552 yılında Kazan Hanlığı'nı işgal etmesiyle başlayıp Perm'e Rus göçmenlerinin ve madencilerinin yerleştirilmesiyle devam eden sürecin Sibir Hanlığı için doğurduğu ve doğurabileceği olumsuz sonuçları görmüştür. Böylece Sibir Hanlığı'nın sınırlarına karşı yavaş yavaş bir tehdit oluşturmaya başlayan Ruslarla mücadele etmeye karar vermiştir. Küçüm Han, Ruslarla olan bu mücadelesinde çevredeki çeşitli yerli kabilelerin yardımını sağlamakla birlikte, esas yardımı Sibirya'ya XIV. yüzyıldan itibaren İslamiyet'i yayma amacıyla gelen gruplardan sağlamıştır ${ }^{6}$. Bunlardan ilki Nakşibendi tarikatına bağlı Buharalı dervişler ve seyitlerdir ki; bölgeye XIV. yüzyıldan itibaren gelmeye başlayan bu dervişler ve seyitlere, Küçüm Han'ın 1572-1573 yıllarında Buhara Hanı II. Abdullah ile yaptığı ittifak görüşmeleri sonucu yenileri dahil edilmiştir ${ }^{7}$. İkincisi ise Kazan Hanlığı'na mensup ve esasen din adamı (hafiz) olan, fakat ticaretle de uğraşan kişilerdir ki; bu kişilerin bir kısmı muhtemelen 1552 yılında Kazan Hanlığı'nın Ruslar tarafından

1 H. Atlasi, Sibir Tarihi, çev. E. Havare, Ankara 2016, s. 19; S. Acar, "Sibir Hanllğı", Doğu Avrupa Türk Tarihi, ed. Osman Karatay - Serkan Acar, İstanbul 2015, s. 783.

2 Çimgi-Tura sözcüğü "Cengiz Han'ın şehri” anlamına gelmektedir. Tümen sözcüğü ise eski Moğolca ve eski Türkçede "10.000 ya da sayılamayacak kadar çok" anlamlarına gelmektedir. A. K. Matveyev, Geografiçeskie Nazvaniya Urala: Toponomiçeskiy Slovar, Yekaterinburg 2008, s. 283-284.

3 Atlasi, a.g.e., s. 20.

4 İ. Topsakal, Sibirya Tarihi, İstanbul 2018, s. 69; Acar, a.g.m., s. 783;

5 PSRL XIII, İmenuemuy Patrierşeyu ili Nikonovskuyu Letopisyu, SPb., 1904, s. 276.

6 Topsakal, a.g.e., s. 162.

7 N. F. Katanov, Predaniya Tobolskih Tatar o Pribttii v 1572 Godu Muhammedanskih Propovednikov v Gorod Isker, ETGM, VII, Tobolsk 1897, s. 57-60. 
işgal edilmesiyle birlikte Sibirya’ya gelmiş, diğer kısmı ise 1564 yılında bizzat Küçüm Han tarafından Kazan'dan getirilmiştir'.

Netice itibariyle Küçüm Han, Sibirya'ya XIV. yüzyıldan itibaren gelmeye başlayan din adamlarına, iktidarı sırasında sürekli yeni kişilerin dahil edilmesini sağlayarak Ruslarla yapacağı mücadeleye dinî bir boyut kazandırmıştır. Kazandırdığı bu dinî boyut sayesinde ise, 1573 yılından 1598 yılına kadar Ruslarla aralıksız olarak mücadele etmiştir.

Çalışmamızda ilk olarak “Küçüm Han'ın Soyu” başlığı altında Küçüm Han'ın, Kazak mı? Şeybani mi? olduğuna dair bahsedilen görüşler değerlendirilecek, daha sonra ise "Küçüm Han'ın Hayatı” başlığı altında Küçüm Han'ın katıldığı savaşlar ve bağımsızlık duygusu hakkında bilgi verilecektir.

\section{Küçüm Han'ın Soyu}

Küçüm Han'ın soyuna dair iki temel görüş bulunmaktadır. Bunlardan ilki; Küçüm Han ile alakalı bazı olaylardan yola çıkılarak yapılmaya çalışılmış ve Küçüm Han, Kazak Orda soyuna bağlanmıştır. Bu görüşe neden olayları ise şu şekilde açıklayabiliriz:

1- P. İ. Nebolsin, "Pokorenie Sibiri” adlı eserinde, 1557 yılında Sibir Hanı Yadigâr'ın, kendisinden vergi toplamak için gelen Rus elçilerine Kazak Hanı ile savaş halinde olduğunu söylediğinden bahsetmekte ve o yıllarda Yadigâr Han'ın Küçüm Han ile savaşmasından yola çıkarak Kazak Hanının Küçüm olduğu yorumunda bulunmaktadır ${ }^{9}$. Fakat Rus yıllıklarındaki 1557 yılı kayıtlarında, Sibir Hanı Yadigâr'ın vergi toplamak için gelen Rus elçilerine Şeybani Hanı ile savaş halinde olduğunu söylediğinden bahsedilmektedir ${ }^{10}$. Dolayısıyla P. İ. Nebolsin'in bu konu çerçevesinde vermiş olduğu bilgilerin doğruluğu boşa çıkmaktadır.

2- Yesipov yıllığında "Küçüm Han, Kazak Orda steplerinden geldi"l1 ifadesi geçmektedir. Fakat bu ifade; M. Karakulak'ın dediği gibi “Küçüm Han’ı Kazak Orda soyuna bağlamamakta, sadece bölgeyi belirtmek için kullanılmaktadır."12 M. Karakulak'ın bu çıkarımını açıklamak için ilk olarak, Şeyban Han'a verilen topraklara bakmak gerekir. Ebu'l Gazi Bahadır Han, Şeyban Han'a verilen topraklardan şu şekilde bahsetmektedir:

8 “Küçüm Han iktidarının ikinci yılında Kazan'a gitti ve Kazan Han'ı Murat'ın kızını eş olarak aldı. Daha sonra ise; çok sayıdaki Çuvaş, abız (hafiz) ve Rus esirle birlikte Sibirya'ya geri döndü." "Remezovskaya Letopis po Miroviçevu Spisku”, Sibirskie Letopisi, SPb., 1907, s. 319-320; Sibir Hanlığ Kronikleri III Remezov Kroniği, ter. F. Ünal, M. Özkan, M. Karakulak, Z. Sever, H. Aslantürk, İstanbul 2020, s. 67.

9 P. İ. Nebolsin, Pokorenie Sibiri, SPb., 1849, s. 38.

10 PSRL XIII, s. 276.

11 "Yesipovskaya Letopis po Spisku Undolskogo", Sibirskie Letopisi, SPb., 1907, s. 186; Sibir Hanliğl Kronikleri I Yesipov Kroniği, ter. F. Ünal, M. Özkan, M. Karakulak, Z. Sever, H. Aslantürk, İstanbul 2020, s. 47-48.

12 M. Karakulak, "Haydut ve Devlet: Yermak'ın Batı Sibirya Seferi”, Çanakkale Araştırmaları Türk Yıllı̆̆ı, sayı 27 (2019), s. 276. 
"Sonra Batu Han, Şeyban Han'a dedi ki: Oturacağın yurt ă̆abeyim ile benim aramda olsun. Illkbaharda Irgaz, Ur; yazın Ural Dağları'na kadar Cayık'ın doğusunu yayla kıl. Kışın Arakurum-Karakurum ve Sır Suyu'nun (Sır Derya) boyu, Çu Suyu'nun ayağı, Sarı Su'nun ayağını kışla kıl, dedi."'13

Bu cümlelerden anlaşılıyor ki; Şeyban Han'a verilen topraklar, XV. yüzyıl itibariyle Kazak Orda'nın kurulduğu sahadır. H. Atlasi'nin dediği gibi “bu topraklarda sırasıyla Şeyban Han, Cuci Buka, Badakul, Mengü Timur ve Küçüm Han'ın dördüncü kuşaktan dedesi Bik Kondu Oglan'ın kardeşi Pulad Han hükümdarlık yapmış, daha sonra ise Pulad Han'ın oğulları Cayık ve Sır Suyu'nun etrafından uzaklaşmışlardır."14 Dolayısıyla bu topraklar zaman içerisinde Kazak Orda'ya geçmiştir ve burada hala yaşamını sürdürmeye devam eden, Bik Kondu Oglan'ın neslinden gelen Küçüm Han ve babası Murtaza’nın da aralarında bulunduğu kesim azınlık durumuna düşmüştür. Fakat Bik Kondu Oglan'ın neslinden gelenler azınlık durumuna düşmüş olsalar da A. İ. Levşin'in, Küçüm Han hakkında vermiş olduğu “babası Murtaza, kendisine Sibir Hanlı̆̆ı'nın başkenti Isker 'il ele geçirmek için bir ordu verdi." ${ }^{16}$ şeklindeki bilgiden yola çıkarak, Kazak Orda topraklarında hala küçük de olsa bir yerel yönetim kurduklarını tahmin edebilir ve Küçüm Han'ın bu topraklardan geldiğini söyleyebiliriz.

Küçüm Han'ın soyuna dair ikinci görüş ise; Şeybanilere mensup olduğudur. Bu görüş ilk kez Küçüm Han'ın yanındaki Karaçi Beylerden biri olan Kadir Ali Bek Celayiri tarafından dile getirilmektedir ${ }^{17}$. Kadir Ali Bek Celayiri’ye göre Küçüm Han'ın soyu şu şekildedir:

"Hacı Muhammed Han bin Bik Kondu Oglan, onun oğlu Muhammed Tik (Mahmudek), onun oğlu Kuluk (Tuluk) Han, onun oğlu Aybak (Abak, İbak, Opak) Han, onun oğlu Murtaza Han, onun oğulları Can Girey Sultan, Akmat Girey Sultan, Küçüm Han. ”18

Fakat Kadir Ali Bek Celayiri tarafindan “Tuluk Han'ın oğlu İbak Han” şeklinde verilen bilginin, Ustjusk (Arhangelsk) yıllığındaki 1505 yılı kayıtlarıyla çeliştiği gözlemlenmektedir ${ }^{19}$.

Nitekim Kadir Ali Bek Celayiri’nin, Küçüm Han’ın soyuna dair verdiği bu bilgilerden yaklaşık yarım asır sonra, Ebu'l Gazi Bahadır Han, XIII-XVII. yüzyıllar arasındaki Türk-

13 Ebu'l Gazi Bahadır Han, Türk'ün Soyağacı Türk Şeceresi, çev. Doktor Rıza Nur, sad. Yunus Yiğit, İstanbul 2009, s. 131; Ebu'l Gazi Bahadır Han, Şecere-yi Türk Türk'ün Soyağacı, haz. Z. Ölmez, Ankara 2021, s. 139.

14 Atlasi, a.g.e., s. 52.

15 İsker kelimesi “Íske-ür” yani “eski tepe, eski bayır” anlamlarına gelmektedir. Atlasi, a.g.e., s. 22.

16 A. İ. Levşin, Opisanie Kirgiz-Kazaçih, ili Kirgiz-Kaysatskih Ord i Stepey, II, SPb., 1832, s. 48.

17 Kadir Ali Bek Celayiri, 1602 yılında Rus Çarı Boris Godunov'a takdim edilmek üzere çevirisini yaptığ1 Reşidüddin Fazlullah-1 Hemedani'nin Camiü't Tevarih adlı eserine kendi döneminde yaşamış bazı kişileri ve onların etrafında gelişen bazı olayları eklemiştir.

18 R. Alimov, Kadir Ali Bek ve Camiü t-Tevarih’i Üzerine Dil İncelemesi, İstanbul Üniversitesi Sosyal Bilimler Enstitüsü, Yayımlanmamış Doktora Tezi, İstanbul 2005, Tenkitli Metin 65a.

19 “... İbak Han’ın oğlu Kuluk (Tuluk) Sultan kardeşleri ve çocuklarlyla birlikte Tümen'den habersiz bir şekilde geldi..." Ustyujskiy Letopisnıy Svod, Moskva 1950, s. 102. 
Moğol soyundan gelen kişileri ve onların etrafında gelişen olayları kaleme aldığ 1 "Şecere-i Türk̂̂” adlı eserinde Küçüm Han'ın soyuna dair yeni bilgiler vermiştir:

“Cengiz Han'ın oğlu Cuci Han, onun oğlu Şeyban Han, onun oğlu Bahadur Han, onun oğlu Cuci Boga, onun oğlu Badakul, onun oğlu Mengü Timur, onun oğlu Bik Kondu Oglan, onun oğlu Ali Oglan, onun oğlu Hacı Muhammed Han, onun oğlu Mahmudek Han, onun oğlu Abak (İbak, Opak) Han, onun oğlu Tuluk Han, onun oğlu Şamay Sultan, onun oğlu Uraz Sultan, onun oğlu Bahadur Sultan. Yukarıda bahsettiğimiz Mahmudek Han'ın, Murtaza Han adında bir oğlu olup, Murtaza Han 'ın da oğlu Küçüm Han'dır. "20

Ebu'l Gazi Bahadır Han tarafindan verilen bu bilgilerde, "Tuluk Han, İbak Han 'ın oğlu” olarak düzeltilmesine rağmen ortaya yeni hataların çıktığı görülmektedir. Bu yeni hatalara değinen tarihçi D. N. Maslyujenko, “Mahmudek'in 1469 yılında öldügüünü, Murtaza'nın ise 1540-1560 yılları civarında yaşadığını, dahası Fyodor Ívanoviç tarafindan Küçüm Han'a gönderilen yarlıkta Küçüm Han 'ın dedesinin İbak Han olarak zikredildiğini '”21 belirtmektedir. Öte yandan tarihçi, Küçüm Han'ın soyuna dair Ş. Mercani tarafından verilen bilgilere dikkat çekmektedir ${ }^{22}$. Ş. Mercani’ye göre ise Küçüm Han'ın soyu şu şekildedir:

"Hacı Muhammed ibn Gali ibn Bik Kondu Oglan ibn Mengü Timur ibn Badakul ibn Cuci Buka ibn Şeyban. Ondan sonraki Sibirya Han'ı oğlu Mahmudek. Daha sonra ise İbrahim (Ibak), Tuluk Hoca, Şamay, Uraz, Bahadır, Murtaza ibn İbrahim ve son olarak Küçüm oldu. ${ }^{23}$

Böylece Ş. Mercani tarafindan verilen bu bilgilerde hem Tuluk Han'ın hem de İbak Han'ın, Şeybani soyu içerisindeki konumunun düzeltildiği görülmektedir.

Netice itibariyle zaman içerisinde çeşitli tarihçiler tarafından Küçüm Han'ın aile üyelerinden bazılarının Şeybani soyu içerisindeki konumlarında türlü değişiklikler yapılmıştır. Fakat tüm bu değişiklere rağmen Küçüm Han'ın Şeybani soyundan geldiği kesin olmakla birlikte günümüzde geçerliliğini hala sürdürmektedir.

\section{Küçüm Han'ın Hayatı}

Kaynaklarda Küçüm Han hakkındaki bilgiler, ilk olarak 1558 yılında Moskova’ya gönderdiği elçilerle birlikte başlamaktadır.

20 Ebu'l Gazi Bahadır Han, Türk'ün Soyağacı, s. 129; Ebu'l Gazi Bahadır Han, Şecere-yi Türk, s. 136-137.

21 “... senin deden İbak Han'ın ve ondan sonra Sibirya tahtına geçen Taybuga soyundan Muhammed'in ödediği vergiler gibi ...” Sobranie Gosudarstvennih Gramot i Dogovorov, II, Moskva 1819, s. 132-134.

22 Diğer taraftan tarihçiye göre Tuluk Han (Hoca)'ın varlığı kaynaklar tarafından doğrulanırken Şamay, Uraz ve Bahadır Hanların varlığı herhangi bir kaynak tarafından doğrulanamamaktadır. D. N. Maslyujenko, "Sibirskaya Vetv Dinastii Şibanidov v İssledovanii Ş. Marcani”, Zolotoordınskoe Obozrenie/ Golden Horde Review, 7 (3), 2019, s. 491. Fakat Ustjusk (Arhangelsk) yıllığında 1505 yılına ilişkin “...Kuluk (Tuluk) Sultan kardeşleri ve çocuklarıla birlikte Tümen'den habersiz bir şekilde geldi...” şeklinde verilen bilgiler, bu kişilerin Tuluk Han'ın kardeşleri ya da çocukları olabileceği ihtimalini doğurmaktadır. Ustyujskiy, s. 102.

23 Ş. Marcani, İzvleçenie Vestey o Sostoyanii Kazani i Bulgara, I, Kazan 2005, s. 130. 
Sibir Hanı Yadigâr, hem Sibir Hanlığı'nı olası bir Moskova tehdidinden korumak hem de devletin güney sınırlarını tehdit eden Şeybanilere karşı destek bulabilmek amacıyla Rus Çarı IV. İvan'a vergi vermeyi kabul ederek, 1558 yılında Çibiçen (Çigiben) adındaki elçiyi Moskova'ya göndermiştir. Diğer taraftan Yadigâr Han'ın böyle bir yola başvurduğunu gören Küçüm Han ve Ahmet Giray Han da aynı amaç doğrultusunda, 1558 yılında Moskova’ya Taşkin ve Mamin Şah adında iki elçi göndermişlerdir. Fakat gönderilen üç elçi de IV. İvan'ın emriyle tutuklanmışlardır ${ }^{24}$. Elçilerin tutuklanmasının nedeni kaynaklar tarafından her ne kadar elçilerin IV. İvan'ın yanına gelirken vergi getirmemelerine bağlansa da ${ }^{25}$ muhtemelen bunun asıl nedeni, IV. İvan'ın hem Sibir Hanlığı'nın mevcut iktidarını hem de onun yerine geçmek isteyen kişileri desteklemekten kaçınması ve dolayısıyla Sibir Hanlığı'nın iç mücadeleler sonucunda yıkılmasını amaçlamasıdır. Nitekim IV. İvan'ın bu düşüncesi gerçekleşmemiş, Küçüm Han, Yadigâr ve Bekbulat Hanları öldürerek abisi Ahmet Giray Han ile birlikte Sibir Hanı olmuştur ${ }^{26}$.

Böylece iktidarının ilk yıllarında Sibir Hanlığı'nın yönetimini abisi Ahmet Giray Han ile paylaşan Küçüm Han, önce devletin manevî yönünü güçlendirmek için Kazan'daki din adamlarının Sibirya'ya gelmesini sağlamıştır27. Daha sonra ise devletin askerî gücünü kuvvetlendirmek için İrtiş ve Tobol civarında bulunan Tatar beyleri ve mirzalarını, Ural dağlarının doğusundaki Başkurtlar, Ostyaklar, Vogullar ve Baraba Çölü’ndeki Tatarları egemenliği altına almıştır² .

Netice itibariyle iktidarının ilk yıllarında genellikle devleti manevî ve askerî açıdan kuvvetlendirmek gibi iç işlerle uğraşan Küçüm Han, abisi Ahmet Giray Han'ın 1567 yılında kayınpederi Şıgay Han tarafından öldürülmesinden sonra ${ }^{29}$ Sibir Hanlığı'’nın tek hanı sıfatıyla devletin dış işleriyle de uğraşmaya başlamıştır. Nitekim Küçüm Han'ın Sibir Hanlığı'nda tek başına iktidar olmasından sonra IV. İvan, 1569 yılında Sibirya’ya elçi göndererek Yadigâr Han döneminde Moskova'ya ödenen vergilerin devam ettirilmesi talebinde bulunmuştur ${ }^{30}$. Rus Çarının bu talebi doğrultusunda Küçüm Han, 1571 yılında Moskova’ya vergi ödemeyi kabul etmiştir; ancak 1570 yılında Knyaz Romodanovskiy aracılığıyla IV. İvan'a ilettiği yarlıkta geçen ifadelerden ${ }^{31}$ anlaşıldığı üzere Moskova'dan herhangi bir çekincesi yoktur.

24 G. Fayzrahmanov, Istoriya Tatar Zapadnoy Sibiri, Kazan 2007, s. 131.

25 Diğer taraftan N. M. Karamzin, Yadigâr Han'ın 1558 yılında vergiyi ödediğini belirtmektedir. N. M. Karamzin, Istoriya Gosudarstva Rossiyskogo, VIII, SPb., 1819, s. 229.

26 "Yesipovskaya Letopis po Spisku Undolskogo", Sibirskie Letopisi, SPb., 1907, s. 186; Sibir Hanlı̆̆l Kronikleri I, s. 49.

27 "Remezovskaya Letopis po Miroviçevu Spisku", Sibirskie Letopisi, SPb., 1907, s. 319-320; Sibir Hanlı̆g Kronikleri III, s. 67.

28 Atlasi, a.g.e., s. 54-55; Fayzahmanov, a.g.e., s. 132; O. Doğan, "Küçüm Han”, DİA, XXVI, Ankara 2002, s. 532.

29 Fayzrahmanov, a.g.e., s. 30

30 Atlasi, a.g.e., s. 56.

31 “... eğer barışmak istersen barışalım, savaşmak istersen savaşalım...” Sobranie, s. 52. 
Diğer taraftan Küçüm Han'ın Moskova'ya karşı vergi verme konusunda 1lımlı davranmasına Kazak Orda Hanı Hak-Nazar ile olan mücadelesi neden olmuştur. Böylece Küçüm Han, Moskova'ya vergi vermeyi kabul ederek hem Kazak Orda ile mücadelesinde dışarıdan gelme ihtimali olan bir tehdidi önlemek hem de kendisine bu mücadele sırasında destekçi bulmak istemiş olmalıdır.

Fakat bu durum Küçüm Han'ın düşündüğü şekilde sonuçlanmamış, Moskova ile Kazak Orda arasında ittifak kurulmuştur. Böylece Moskova ile yaptığı anlaşmaları sonlandıran Küçüm Han, ilk iş olarak 20 Temmuz 1573 tarihinde yeğeni Mametkul (Muhammed Kul)'u birkaç mirza ile birlikte Çusova Nehri'ne göndererek, burada Moskova'ya hizmet eden Ostyak ve Vogulların birçoğunu öldürtmüş, daha sonra ise yine aynı tarihlerde IV. İvan tarafından Kazak Orda ile anlaşma yapmak için görevlendirilen Tretyak Çebukov'un başında bulunduğu elçilik heyetini ortadan kaldırtmıştır ${ }^{32}$.

Böylece Küçüm Han, bir yandan Kazak Orda ile mücadele ederken diğer yandan en son gerçekleşen olaylarla birlikte Moskova ile de mücadele etmeye başlamıştır. Bu durum karşısında yeni ittifak arayışlarına giren Küçüm Han, oğlu Ali’yi, Nogay Mirzalarından Din Ahmet'in kızıyla; kızlarından birini ise, Nogay Orda Han'1 Akmirza ile evlendirmiştir ${ }^{33}$.

Ayrıca Tobolsk, Tuba, Turinsk, Tara ve Tomsk gibi şehirlerde yaşayan pek çok Buhara ailesinin desteğini almak $^{34}$ ve Şamanist, Animist inançlara sahip olan Ostyak, Vogul, Samoyed gibi kabileleri İslamiyet etrafında toplayarak Sibir Hanlığı sınırları içerisinde dinî birliği sağlamak ${ }^{35}$ amacıyla Buhara Hanı II. Abdullah Han'dan, Sibir Hanlığı'nın başkenti olan İsker'e derviş ve seyitlerin gönderilmesini talep etmiştir ${ }^{36}$.

Nitekim Küçüm Han'ın Sibir Hanlığı sınırları içerisindeki farklı inançlara sahip olan kabileleri İslamiyet etrafında toplama fikri, bahsettiğimiz kabilelerin yaşam şartları dolayısıyla gerçekleşme imkânı bulamamıştır ${ }^{37}$.

Küçüm Han yaptığı bu ittifaklarla devleti güçlendirirken, yeğeni Mametkul'u XVI. yüzyıldan itibaren Rusların Sibirya’ya ilerleyişinin önemli sembollerinden olan ve Perm

32 "Stroganovskaya Letopis po Spiku Spasskago", Sibirskie Letopisi, SPb., 1907, s. 6; Sibir Hanlı̆̆ Kronikleri II Stroganov Kroniği, ter. F. Ünal, M. Özkan, M. Karakulak, Z. Sever, H. Aslantürk, İstanbul 2020, s. 48.

33 Fayzrahmanov, a.g.e., s. 135. Küçüm Han'ın Nogay Orda ile yakınlaşmasının sebebi; ikisinin de ortak düşmanlarının Kazak Orda olmasıdır. V. V. Velyaminov-Zernov, Issledovanie o Kasimovskih Tsaryah $i$ Tsareviçah, II, SPb., 1864, s. 323.

34 İ. E. Fişer, Sibirskaya İstoriya s Samogo Otkritiya Sibiri do Zavoevaniya Sey Zemli Rossiyskim Orujiem, SPb., 1774, s. 98.

35 Topsakal, a.g.e., s. 71.

36 Ürgeç şehrinden Yarım Seyid ve Şerbeti Şeyh gönderilmiştir. Katanov, a.g.e., s. 57-60.

37 Topsakal, a.g.e., s. 71. 
civarında tuz işletmeciliği yapan Stroganov ailesii ${ }^{38}$ ile savaşmaya göndermiştir. Bunun üzerine Stroganovlar, Moskova’ya haber göndererek yardım istemiş ve kendilerine 30 Mayıs 1574'te IV. İvan tarafindan 'Sibirya'daki Yakov ve Grigory, Ostyak, Vogul, Yugor, Samoyed ve paralı Kozakları toplayı savaşmaya göndersin. Bizim için Sibirya'dan esir ve vergi getirsin. " ${ }^{39}$ şeklinde bir yarlık verilmiştir. Ayrıca yine Stroganovların bölgeye Sibir Hanlığı'ndan gelen akınların durdurulması amacıyla askerî şehirlerin kurulması ricası da IV. İvan tarafindan kabul edilmiş ve ilk olarak Sılva Nehri'nde, daha sonra ise Tahçei'de askerî şehir kurulmuştur ${ }^{40}$. Nitekim Stroganovların kendi işletmelerini korumak için gösterdiği bu çabalar sonuçsuz kalmıştır. Saldırılarına devam eden Mametkul ise, Orol çevresi hariç olmak üzere Kosva, Kama, Obva, Yayva ve Çusova'daki Stroganovlara ait tüm işletmeleri ele geçirmiştir ${ }^{41}$.

Bunun üzerine Stroganovlar, 1582 y1lında IV. İvan'dan izinsiz bir şekilde Volga'da soygunculuklarıyla ünlenmiş olan Kozak Atamanı Yermak Timofeyeviç ${ }^{42}$ ve onun emri altında bulunan Kozakları Çusova'ya davet ederek, bu kişileri 1 Eylül 1582 tarihinde Küçüm Han ile savaşması için Sibirya'ya göndermiştir ${ }^{43}$. Çusova Nehri'nden yola çıkan Kozaklar, Serebrenaya, Boronçüka, Tagil, Tura, Tobol Nehirleri boyunca ilerleyerek Sibir Hanlığı'nın başkenti İsker'e ulaşmaya çalışmışlardır ${ }^{44}$. Kozaklar Tagil Nehri'ne vardıklarında adı kaynaklar tarafından belirtilmeyen bir Tatar mirzası ile yaptıkları savaşta yenilgiye uğramışlardır. Fakat bu durum Kozakların ilerleyişine engel olmamış ve Tura Nehri boyunca ilerlemeye devam etmişlerdir. Kozakların bu nehir üzerinde hareket ettiğini öğrenen Yepança liderliğindeki Tatarlar, Kozakların İsker'e varmasına engel olmaya çalışsalar da modern silahlara sahip olan Kozaklara karşı hiçbir mukavemet gösterememişlerdir ${ }^{45}$. Böylece Tobol Nehri boyunca yollarına devam eden Kozaklar, Babasan (Baba Hasan) adı verilen yerde Mametkul liderliğindeki Tatarlarla karşılamışlardır. Nitekim gerçekleşen bu mücadelede iki taraf arasında kazanan olmamıştır. Bu savaştan sonra İsker'e daha da yaklaşan Kozaklar,

38 XV. yüzyılda Rusya'nın kuzeyinde tuz madenlerini işleten bu aile, 1552 yılında Moskova'nın Kazan Hanlığı'nı işgaliyle birlikte Perm civarına yerleşmiştir. Moskova tarafından vergi muafiyeti başta olmak üzere çeşitli imtiyazlar verilmiş; bunun karşılığında Moskova'nın Sibirya’ya ilerleyişinde önemli vazifeler üstlenmişlerdir. Topsakal, a.g.e., s. 91-92.

39 G. F. Miller, İstoriya Sibiri, Moskva 1937, s. 340.

40 R. G. Skrınnikov, Sibirskaya Ekspeditsiya Yermaka, Novosibirsk 1986, s. 100.

41 R. G. Skrınnikov, Yermak, Moskva 2008, s. 49.

42 Adı Rus kaynaklarında ilk defa 8 Temmuz 1581 tarihinde Volga'da Nogay Orda’ya karşı gerçekleştirdiği soygunlarda bahsedilmiş ve daha sonra ise yine Volga'da birçok soygun girişiminde bulunmuştur. 1582 yılında ise, Storganovların ricası üzerine Çusova'ya gelmiş ve Stroganovlardan aldığı destekle birlikte 1 Eylül 1582'den 5 Ağustos 1584'te öldüğü güne kadar Küçüm Han ile savaşmıştır. M. T. Yılmaz, Yermak Timofeyeviç ve Kazakların Sibirya Seferi, İstanbul Üniversitesi Sosyal Bilimler Enstitüsü, Yayımlanmamış Yüksek Lisans Tezi, İstanbul 2020, s. 23-25, 30-36, 54-69.

43 Dopolneniya $k$ Aktam İstoriçeskim, I, SPb., 1846, s. 184.

44 "Yesipovskaya Letopis po Pogodinskomu Spisku", Sibirskie Letopisi, SPb., 1907, s. 276.

45 "Remezovskaya Letopis po Miroviçevu Spisku”, Sibirskie Letopisi, SPb., 1907, s. 317; Sibir Hanlı̆̆ Kronikleri III, s. 78-83. 
Karaça ve Atika adlı Tatar beylerinin yurtlarını ele geçirmişler ve Çuvaş Burnu'nda Mametkul'un liderliğindeki Tatarlarla tekrar karşı karşıya gelmişlerdir. Sibir Hanlığı'nın kaderini belirleyen bu savaşta Muhammed Kul'un yaralanması üzerine Hanti ve Mansiler Sibir Tatarlarına verdiği desteği geri çekmişlerdir ${ }^{46}$. Böylece zayıflayan Tatar ordusu 26 Ekim 1582 tarihinde İsker'i terk ederek, Abalak'a çekilmiştir ${ }^{47}$.

Kozakların İsker'i işgaliyle birlikte Küçüm Han'ın etrafında bulunan Ostyak Knyazi Boyar, Tatar Beyi Süklem ve İşberdey gibi kişiler Yermak'ın zaferini kutlayarak Moskova’ya bağlılıklarını bildirmişlerdir ${ }^{48}$.

Diğer taraftan geri çekilen Tatarlar, kısa süre içerisinde toparlanmayı başararak, Abalak’a balık tutmaya gelen Kozak grubunu ağır bir yenilgiye uğratmışlardır ${ }^{49}$. Fakat Tatarların, Kozaklara karşı sağladıkları bu başarı uzun sürmemiştir.

Tatar mirzalarından Senbaht Tagin (Tigin)'i yanına çekmeyi başaran Yermak, Küçüm Han'ın yeğeni Mametkul'un Vagay Nehri'nde olduğunu öğrenmesi üzerine, Kozakları Mametkul ile savaşmaya göndermiştir. Gündüz gerçekleştirdikleri ilk saldırıda herhangi bir sonuç elde edemeyen Kozaklar, gecenin gelmesiyle birlikte yaptıkları ikinci saldırıda çok sayıda Tatarı öldürmüşler ve Mametkul'u esir almışlardır ${ }^{50}$.

Böylece Tatarların aldıkları yenilgiler sonucu, Küçüm Han’a bağlı kişiler tek tek isyan etmeye başlamışlardır. Bekbulat' $1 n$ oğlu Seydak' $n^{51}$ önderliğinde başlayan isyan girişimi Karaça'nın katılmasıyla devam etmiştir. Fakat Karaça daha sonra Kozaklarla anlaşmaktan vazgeçerek, Kozak Atamanlarından İvan Koltsov'u yanındaki kırk adamıyla birlikte pusuya düşürmüştür. Ayrıca bu olaydan güç alan Tatarlar İsker şehrini kuşatmışlar, ama başarılı olamamışlardır ${ }^{52}$.

46 "Stroganovskaya Letopis po Spisku Spasskago", Sibirskie Letopisi, SPb., 1907, s. 20-26; Sibir Hanlı̆̆ Kronikleri II, s. 64; Topsakal, a.g.e., s. 95; O. Doğan, a.g.m., s. 533.

47 N. Witsen, Noord en Oost Tatarye, Amsterdam 1785, s. 738; Y1lmaz, a.g.t., s. 58.

48 "Stroganovskaya Letopis po Spisku Spasskago", Sibirskie Letopisi, SPb., 1907, s. 26; Sibir Hanlı̆ğ Kronikleri II, s. 69.

49 Abalak’ta öldürülen Kozak grubunda kimlerin olduğuna dair çeşitli söylentiler vardır. Skrınnikov, Sibirskaya, s. 220; Y1lmaz, a.g.t., s. 59-60.

50 "Stroganovskaya Letopis po Spisku Spasskago", Sibirskie Letopisi, SPb., 1907, s. 27- 28; Sibir Hanlığı Kronikleri II, s. 70-71. Diğer taraftan savaşın gerçekleştiği tarih Sibir yıllıkları tarafından yanlış verilmektedir. Y1lmaz, a.g.t., s. 60.

51 Taybuga soyundan gelen Sibir Hanı Bekbulat'ın oğludur. Babası Küçüm Han tarafından öldürülünce ilk olarak Buhara'ya kaçmış, daha sonra ise Küçüm Han'ın yanına gelerek ordusunda yer almıştır. Yermak Timofeyeviç önderliğindeki Kozakların Sibirya’ya saldırdığı zamanlarda Küçüm Han'a karşı isyan etmiş, Yermak’ın ölümünden sonra ise kısa süreliğine Küçüm Han ile tekrar barışsa da ilerleyen zamanlarda kurnaz davranarak Sibir Hanlı̆̆g'nın başkentini ele geçirmeyi başarmıştır. Yılmaz, a.g.t., s. 40, 61, 69.

52 "Stroganovskaya Letopis po Spisku Spasskago", Sibirskie Letopisi, SPb., 1907, s. 33-36; Sibir Hanllğ Kronikleri II, s. 75-76; İ. Topsakal, a.g.e., s. 97. 
Başlangıcından itibaren Tatarlar ve Kozaklar arasında bitmeyen mücadele 1 Ağustos 1584 'ten itibaren yeni bir hal almıştır. Bu tarihlerde Yermak'ın yanına gelen Buharalı tüccarlar, Tatarların ticaretlerine engel olduklarını belirterek, Kozaklardan Vagay Nehri'nde kendilerine yardım etmelerini istemişlerdir. Nitekim yardıma gitmeye karar veren aralarında Yermak'ın da olduğu Kozak grubu, Vagay Nehri'nde Buharalılar ve Tatarlar tarafindan pusuya düşürülmüştür. Tatarların bu saldırısı sonucunda ise çoğu Kozak öldürülmüş, Yermak ise kaçmaya çalışırken suya düşüp boğulmuştur ${ }^{53}$.

Yermak'ın ölümünden sonra Kozakların birçoğu İsker'i terk etmiştir ${ }^{54}$. Bunu firsat bilen Küçüm Han ise, oğlu Aley (Ali)'i başkenti geri almak için gönderdiyse de Taybuga ailesinden Bekbulat'ın oğlu Seydak başkenti ele geçirmeyi başarmış ve Aley'i şehirden kovmuştur ${ }^{55}$. Bu olaydan bir süre sonra İsker, Küçüm Han ve Seydak taraftarları olarak ikiye bölünmüş ve bu bölünme ise, Tatarları zayıf düşürerek Rusların İsker'i ikinci kez ele geçirmelerine zemin hazırlamıştır. Olayların böyle bir hal almasının sebebi, bazı tarihçiler tarafından Seydak'ın intikamcı ve açgözlü tavırlarına bağlansa $\mathrm{da}^{56}$ bu durumu tarafsız bir bakış açısıyla incelemek son derece önemlidir. Her ne kadar Küçüm Han'ın Sibir Hanlığı'nda iktidara geldikten sonra başarılı kararlar aldığını söylesek de Seydak'ın kendi iktidarına karşı sürdürmüş olduğu değişken tutumlarını maalesef iyi gözlemleyememiştir.

Nitekim 1588 yılında Seydak, Ruslar tarafından esir alınmış ve İsker artık Rusların kontrolüne geçmiştir. Bu tarihten itibaren Küçüm Han, 1598 yılına kadar bölgeden Rusları kovmak için savaşmış ve bu uğurda oğlu Ali hariç, tüm ailesini Ruslara esir vermesi de dahil olmak üzere çok şey kaybetmiştir ${ }^{57} .1598$ yılında ise A. M. Voyeykov'un, Çar Boris Godunov'un emri altına girme isteğini “Ben sağllklıyken Çar'ın mektubuna rağmen onun yanına kendi etrafimdakilerle gitmedim. O dönemde ben tamamen sağlıklıydım. Şimdi benim kılıç altına girmeme ne sebep var? Ben şimdi sağır ve görmez oldum. Her bir şeyden mahrum kaldım. Benim tüccar oğlum Asmanak’ı aldılar. Bütün oğullarımı aldıklarında Asmanak

53 "Stroganovskaya Letopis po Spisku Spasskago", Sibirskie Letopisi, SPb., 1907, s. 33; Sibir Hanlığl Kronikleri II, s. 78-81.

54 "Stroganovskaya Letopis po Spisku Spasskago", Sibirskie Letopisi, SPb., 1907, s. 36; Sibir Hanlı̆ğ Kronikleri II, s. 81

55 Atlasi, a.g.e., s. 93.

56 Atlasi, a.g.e., s. 99.

57 İlk olarak 1 Ağustos 1591 tarihinde Tobolsk şehri Askerî Valisi Knyaz V.V. Koltsov-Mosalskiy'nin İşim Nehri'ne yakın olan Çil-göl'de Küçüm Han'a saldırması sonucu oğlu Ebulhayr ve onun iki hatunu tutsak edilmiştir. İkinci ve son olarak ise 20 Ağustos 1598 tarihinde Tara şehri Askerî Valisi A. M. Voyeykov'un Ob Nehri'ne yakın olan Ormın çayırlığına saldırması sonucu oğulları Asmanak, Şaim, Bipadşah, Mulla, Kömeş, Kanay; hatunları (diğer taraftan H. Atlasi bazılarının Küçüm Han'ın cariyesi olabileceğini belirtmektedir.) Sultanım, Sevdican, Candevlet, Aktolın, Aksöyerek, Şögleli (Şevleni), Kobıl, Cebeşen ve kızları Tolınbike, Dörerpadişah, Matur (Mondur), Karacan, Gölsafet, Akhanım, Asıfsultan, Kumız; büyük oğlu Ali'nin hatunu Hanzade ve onun oğlu Cansur, ikinci oğlu Kanay'ın hatunu Danay ve onun kızı Navruzbike; mirzalarından Din Muhammed ve onun kardeşi Lale Tutay, Baytirek ve onun hatunları Tuka, İsenkilde, Karayavdı; kendi kardeşi Altın (İliten) esir edilip Moskova'ya gönderilmiştir. Atlasi, a.g.e., s. 102, 116-117. 
alınmasaydı ben daha da yaşardım. Şimdi ben Nogaylara gideceğim. " 58 şeklindeki sözlerle reddederek Nogayların ${ }^{59}$ yanına gitmiş ve hayatının son zamanlarını orada geçirmiştir.

\section{Sonuç}

Kaynaklar tarafından Şeybani soyundan geldiği doğrulanan Küçüm Han, 1563 yılında ağabeyi Ahmet Giray Han ile birlikte Sibir Hanlığı'nı ele geçirip burada hüküm süren Taybuga hâkimiyetine son vermiştir.

Genel itibariyle Küçüm Han, Ruslara karşı kendisinin selefi olan Yadigâr Han'ın tam zıttı bir davranış sergilemiştir. İktidarının ilk yıllarında devleti manevî ve askerî yönden güçlendirmiştir. 1573 yılından itibaren ise Sibirya' daki Rus yayılmacılığına karşı çıkmıştır. Devletin bağımsızlığı yolunda önemli girişimlerde bulunmuştur.

Nitekim Küçüm Han'ın bu bağımsızlığı sağlama girişimleri, Stroganovlar tarafindan desteklenen Kozakların seferleri ile kesintiye uğramıştır. Kozakların Sibir Hanlığı'nın başkenti İsker'i işgal etmesi sonucu geri çekilmek zorunda kalmıştır. Fakat bağımsızlığından ödün vermeyen Küçüm Han, 1584 yılında Kozak Atamanı Yermak Timofeyeviç’i öldürmeyi başarmıştır. Öte yandan lehine gerçekleştirdiği bu durumu değerlendirememiştir. Buna rağmen Ruslarla olan mücadelesini 1598 yılına kadar sürdürmüştür.

Küçüm Han'ın 1563 yılından sonraki hayatına ilişkin detaylı bilgilere ulaşmak mümkün iken bu tarihten öncesine dair herhangi bir bilgi elde edilememiştir. Bu boşluğun doldurulması için kapsamlı araştırmalara ihtiyaç olduğu kanaatindeyiz.

Hakem Değerlendirmesi: Dış bağımsız.

Çıkar Çatışması: Yazarlar çıkar çatışması bildirmemiştir.

Finansal Destek: Yazarlar bu çalışma için finansal destek almadığını beyan etmiştir.

Peer-review: Externally peer-reviewed.

Conflict of Interest: The authors have no conflict of interest to declare.

Grant Support: The authors declared that this study has received no financial support.

58 Sibirskiy Vestnik, nr. 39, 9 Aprelya 1893, s. 3.

59 H. Atlasi bu görüşe katılmayıp Ebul Gazi’nin “Küçüm Han'ın kendisi kaçıp Mangıt halkı arasında rahmetine kavuştu." şeklindeki ifadesini savunmaktadır. Bunu ise; Mangıt kabilesinin Buhara yöresinde Ruslara bağl1 olmayan bir kabile olması ve dolayısıyla Küçüm Han'ın o bölgede rahatça hareket edebileceği düşüncesiyle açıklamaktadır. Atlasi, a.g.e., s. 122. Fakat bizim düşüncemize göre burada Ebul Gazi’nin bahsettiği "Manglt kabilesi" Nogay ulusunu temsil etmektedir. Diğer taraftan Ş. Marcani ise, "Küçüm Han memleketini koruyamadığ için Başkurtlar arasına gidip vefat etti.” demektedir. Marcani, a.g.e., s. 130. Fakat bunu kanttlayabilecek herhangi bir delil yoktur. 


\section{Kaynakça/References}

Acar, S., "Sibir Hanlığı", Doğu Avrupa Türk Tarihi, ed. Osman Karatay - Serkan Acar, Kitabevi Yayınları, İstanbul 2015, s. 781-797.

Alimov, R., Kadir Ali Bek ve Camiü 't-Tevarih ’i Üzerine Dil İncelemesi, İstanbul Üniversitesi Sosyal Bilimler Enstitüsü, Yayımlanmamış Doktora Tezi, İstanbul 2005.

Atlasi, H., Sibir Tarihi, çev. E. Havare, TTK, Ankara 2016.

Doğan, O., “Küçüm Han”, DİA, XXVI, Ankara 2002, s. 532-533.

Dopolneniya k Aktam İstoriçeskim, I, Tip. II Otdeleniya Sobstvennoy E. İ. V. Kantselyarii, SPb., 1846.

Ebu'l Gazi Bahadır Han, Şecere-yi Türk Türk’ün Soyağacı, haz. Z. Ölmez, BilgeSu Yayınc1lık, Ankara 2021.

Ebu’l Gazi Bahadır Han, Türk’ün Soyağacı Türk Şeceresi, çev. Doktor Rıza Nur, sad. Yunus Yiğit, İlgi Kültür Sanat Yayınları, İstanbul 2009.

Fayzrahmanov, G., Istoriya Tatar Zapadnoy Sibiri, FEN, Kazan 2007.

Fişer, İ. E., Sibirskaya İstoriya s Samogo Otkritiya Sibiri do Zavoevaniya Sey Zemli Rossiyskim Orujiem, Pri İmp. Akad. Nauk, SPb., 1774.

Karakulak, M., “Haydut ve Devlet: Yermak’ın Batı Sibirya Seferi”, Çanakkale Araştırmaları Türk Yıllı̆̆ı, say1 27 (2019), s. 273-296.

Karamzin, N. M., Istoriya Gosudarstva Rossiyskogo, VIII, Tip. N. Greça, SPb., 1819.

Katanov, N. F., Predaniya Tobolskih Tatar o Pribıtii v 1572 Godu Muhammedanskih Propovednikov v Gorod Ísker, ETGM, VII, Gubernskaya Tipografiy, Tobolsk 1897.

Levşin, A. İ., Opisanie Kirgiz-Kazaçih, ili Kirgiz-Kaysatskih Ord i Stepey, II. Tip. Karla Krayya, SPb., 1832. Marcani, Ş., İzvleçenie Vestey o Sostoyanii Kazani i Bulgara, I, İman, Kazan 2005.

Maslyujenko, D. N., "Sibirskaya Vetv Dinastii Şibanidov v İssledovanii Ş. Marcani”, Zolotoordınskoe Obozrenie/ Golden Horde Review, 7 (3), 2019, s. 485-496.

Matveyev, A. K., Geografiçeskie Nazvaniya Urala: Toponomiçeskiy Slovar, Sokrat, Yekaterinburg 2008.

Miller, G. F., İstoriya Sibiri, İzdatelstvo Akademii Nauk SSSR, Moskva 1937.

Nebolsin, P. İ., Pokorenie Sibiri, Veçe, SPb., 1849.

PSRL XIII, İmenuemıy Patrierşeyu ili Nikonovskuyu Letopisyu, Tipografiya İ. N. Skorohodova, SPb., 1904.

“Remezovskaya Letopis po Miroviçevu Spisku”, Sibirskie Letopisi, İzdanie İmparatorskoy Arherografiçeskoy Komissii, SPb., 1907, s. 312-366.

Sibir Hanlı̆̆g Kronikleri I Yesipov Kroniği, ter. F. Ünal, M. Özkan, M. Karakulak, Z. Sever, H. Aslantürk, Ötüken Neşriyat, İstanbul 2020.

Sibir Hanlığ Kronikleri II Stroganov Kroniğgi, ter. F. Ünal, M. Özkan, M. Karakulak, Z. Sever, H. Aslantürk, Ötüken Neşriyat, İstanbul 2020.

Sibir Hanliğg Kronikleri III Remezov Kroniği, ter. F. Ünal, M. Özkan, M. Karakulak, Z. Sever, H. Aslantürk, Ötüken Neşriyat, İstanbul 2020.

Skrınnikov, R. G., Sibirskaya Ekspeditsiya Yermaka, Nauka, Novosibirsk 1986. Yermak, Molodoya Gvardiya, Moskva 2008.

Sobranie Gosudarstvennıh Gramot i Dogovorov, II, Tip. Selivanovskogo, Moskva 1819. 
“Stroganovskaya Letopis po Spiku Spasskago", Sibirskie Letopisi, İzdanie İmparatorskoy Arherografiçeskoy Komissii, SPb., 1907, s. 1-46.

Topsakal, İ., Sibirya Tarihi, Ötüken Neşriyat, İstanbul 2018.

Ustyujskiy Letopisniy Svod, Akad. Nauk SSSR, Moskva 1950.

Velyaminov-Zernov, V. V., İssledovanie o Kasimovskih Tsaryah i Tsareviçah, II, Tip. İmp. Akad. Nauk, SPb., 1864.

Witsen, N., Noord en Oost Tatarye, Boekverkooper op de Nieuwen-dyk, Amsterdam 1785.

"Yesipovskaya Letopis po Pogodinskomu Spisku", Sibirskie Letopisi, İzdanie İmparatorskoy Arherografiçeskoy Komissii, SPb., 1907, s. 271-295.

"Yesipovskaya Letopis po Spisku Undolskogo", Sibirskie Letopisi, İzdanie İmparatorskoy Arherografiçeskoy Komissii, SPb., 1907, s. 171-240.

Yılmaz, M. T., Yermak Timofeyeviç ve Kazakların Sibirya Seferi, İstanbul Üniversitesi Sosyal Bilimler Enstitüsü, Yayımlanmamış Yüksek Lisans Tezi, İstanbul 2020.

\section{Gazeteler}

Sibirskiy Vestnik, nr. 39, 9 Aprelya 1893. 
